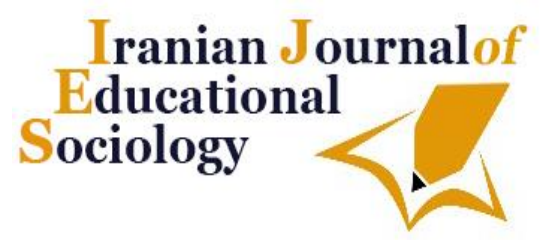

Iranian journal of educational Sociology

(Interdisciplinary Journal of Education)

Available online at: http://www.iase-idje.ir/ Volume 2, Number 3, September 2019

\title{
A Model for the Effectiveness of Organizational Excellence and Agility in Urban Management on Physical, Social and Cultural Dimensions of Tehran khak Sefid Area
}

\author{
Maryam Rashidian ${ }^{1}$, Rashid Zolfaghari zafarani ${ }^{2}$ \\ 1. PhD student in Educational Management, Islamic Azad University, Roudehen Branch. Tehran Iran. \\ 2. Assistant Professor and Faculty Member of Islamic Azad University, Roudehen Branch, Roudehen, Tehran, Iran.
}

\section{Article history:}

Received date: 25 January 2019

Review date: 18 March 2019

Accepted date: 25 May 2019

\section{Keywords:}

Effectiveness, Organizational Excellence, Organizational Agility, Urban Management, Physical, Social and Cultural Dimensions

\begin{abstract}
Purpose: The purpose of this study was to present a model for the effectiveness of organizational excellence and agility in urban management on physical, social and cultural dimensions of Tehran white soil area.
\end{abstract}

Methodology: The purpose of this study was applied in terms of purpose and data analysis was mixed. The population consisted of all 632 employees of the 4th district of Tehran, out of which 240 were selected according to Kerjeci and Morgan table by simple stratified random sampling. The research instrument consisted of three researcher-made questionnaires including Urban Management Excellence Questionnaire consisting of 32 items, Agility Questionnaire in Urban Management consisting of 41 items, and Physical and Social and Cultural Status Assessment Questionnaire of White Land including 27 items. For their reliability after a pilot run among 40 statistical samples using Cronbach's alpha, the reliability value of 0.802 for Urban Management Excellence Questionnaire, 0.816 reliability for Urban Management Agility Questionnaire and 0.849 for Questionnaire of physical, social and cultural status of white soil area was obtained, Data were analyzed descriptively and inferentially.

Findings: The results of data analysis showed that from the perspective of Tehran's four city municipality employees, factors (value added in the workplace, proper leadership in the workplace, process management in the workplace, and nurturing creativity in the workplace) have an impact on urban management excellence.

Conclusion: Finally, the model includes the components of accountability, growth and learning, competence, flexibility, speed of action, value-added, sound leadership, process management and nurturing creativity.

Please cite this article as: Rashidian M, Zolfaghari zafaranii R. (2019). A Model for the Effectiveness of Organizational Excellence and Agility in Urban Management on Physical, Social and Cultural Dimensions of Tehran khak Sefid Area. Iranian journal of educational Sociology. 2(3): 184-198.

\footnotetext{
* Corresponding Author Email: Rashid_zo@yahoo.com
} 


\section{Introduction}

Today, at the level of cities, especially the major cities of developing countries, the concept of citizenship, participation and citizenship is very important. The relevance of studies on the problems of cities and citizens on the one hand and the management of city affairs on the other hand show that the existing management system does not have the authority to solve its problems. It does not have the power and mechanism to deal with the problems ahead (Burkpour, Asadi, 2009).

In this regard, with increasing population and migration to cities and urbanization problems, which has increased the volume of demand for utilities, municipal units are facing financial problems, which necessitate more efficient urban management for municipal administration. (Ebrahimian Jollodar, Ebrahimian Jollodar, 2011). On the other hand, urban management models in Iran have been mainly imported models. These models have not achieved the desired goals despite responding to the needs of target communities due to their conflict with the culture and social needs of the community. This situation, even if it can gradually bring the citizen's mentality to the needs, contexts and conditions for real and purposeful participation, certainly cannot solve the accumulated problems of citizens (Gholipour, 2011). In addition, people have to go to the public sector to meet many of their needs and expect to streamline things, expedite workflow, appropriate employee behavior and increase productivity in the public sector. Therefore, municipalities, as one of the government agencies and lack of competitors and the constant need of the people for this sector, are less likely to pay attention to the issue of agility (Bagherzadeh, 2010).

Today's organizations are faced with many challenges including the push for greater transparency and accountability, limited and complete funding, increased tasks and activities, rapid technology changes, the expectation of fast quality services, so today's world is the age. Developments are ongoing and an organization can succeed in this dynamic environment, moving forward with agility and adapting to conditions (Gholamzadeh, 2016). Agility is a set of abilities and competencies that help an organization survive and thrive in the business environment, based on integrating information technology, employees, work processes in a homogeneous and flexible system (Jafarnejad, 2015). If government agencies cannot move towards agile production, standards in these organizations will be seriously endangered (Bandarian, 2013).

Agile as a 21 st Century paradigm, it has many supporters and has been presented as a successful strategy for responding to rapid changes and varied customer needs. Therefore, the need to identify the agility principles of different types of organizations and to provide them with a suitable model can be effective in influencing organizational performance. The reality is that many large organizations have either been shut down or shut down for lack of agility, and many bureaucracies and government agencies are lacking in efficiency and effectiveness, and with changes to it does not serve the people. It should be noted that agility in the organization can be defined in any area. Whether bureaucratic and government agencies, manufacturing companies and organizations, service organizations and any set of products or services offered to the audience, this agility and consistency with changes and recognition of the audience's needs and optimal use of Technology can be defined in all organizations mentioned above (Nazemzadeh, 2015).

Other variables of the present study are the role of "organizational excellence" in urban management. One of the logical, important and inevitable requirements and requirements for any city that wants to be an active and dynamic presence in the world is to move on the path of progress, progress and achievement of organizational excellence, which is called scientifically development. . Managing development is a process whereby the level of knowledge and skills and information of the three advanced levels of management will provide the conditions necessary for the development of a set of talents and abilities of this category. The organizational excellence model is also a powerful operational tool that can be used for a variety of purposes, but it should be noted that organizational excellence is not a theoretical and 
theoretical conception, but rather an evidence-based, tangible and evidence-based outcome. The European Foundation for Quality Management (1999) considers organizational excellence models as a holistic tool that helps managers with a holistic approach to all aspects of their organizations to better understand their organization. To help, These models are used to measure and compare the performance of organizations, while enabling an organization to evaluate their success in implementing programs at different times, allowing them to measure their performance. Compare with other organizations, especially the best ones (EFQM, 1999).

The Peters \& Waterman model of excellence, the model used in this study, as the first model of organizational excellence in the world and can be applied to other societies and their organizations, especially to society, in terms of taking away the principles, concepts, space and general rules. Our progress will be effective. On the other hand, given the discussion of joining the WTO, the country's industry must inevitably begin or complete this process as soon as practicable, and managers as the final decision-maker play a key role in moving towards The productivity, promotion and excellence of organizations are responsible. Due to the new foundations of urban management, the organization should be able to make the best use of employee participation towards organizational excellence and agility, though because it does not compete with other organizations; it is less likely to move forward, given that, there are enough potentials culturally and socially to witness the excellence of urban management in the better management of urban affairs (Tehran Municipality Department of Social and Cultural Studies, 2011). Paid:

The concept of agility in organizations: Organizational agility is a relatively new concept, this concept first followed by a meeting of many industry experts and executives to find out the causes of corporate helplessness in addressing environmental challenges and changes in a report entitled Manufacturing Strategy In the 21 st century, the views of industrialists were published by the Yakuka Institute and introduced to everyone (Jafarnejad, Shekhi, 2007). Subsequently, many scholars, the oldest and most famous of who are Kidd (1994), Goldman (1995), Yusuf, Sarhadi, Gunasekaran (1999), Sharifi and Zhang (1999), Gunaskaran (1999) and others, have developed this concept. Since the word agility was coined to make the manufacturing industry more competitive and because of the increasing rate of change in the business environment, it was initially found in most agility texts, they talked about agility in order to make the organization competitive, and in fact agility was considered the solution to make the manufacturing organizations more competitive. Some have introduced agility as a successful application of the fundamentals of competitiveness such as speed, flexibility, innovation and quality by integrating recyclable resources and best practices for delivering customer-oriented products and services in a fast changing environment (Mohammadi, Amiri, 2012).

At the same time, each organization seems to require a specific definition of agility depending on its type, characteristics and requirements, as well as the level of agility the organization needs, and therefore many definitions have been provided in this area. Here are some of the definitions: Yakoka Institute defines agile production as a system with soft and hard technology capabilities, trained human resources and information to meet rapidly changing needs. According to Kidd (1994) agile organization, high-tech organization individuals and processes to meet customer demands and to deliver high quality products and services, high-value products and services, value driven content, drive key competencies, responsiveness They summarized environmental and social issues, integrating different technologies, responding to change and uncertainty, integrating within and between organizations. Alshayb (2015) believes that agile organizations seek to satisfy their customers and employees and must be responsive to constant changes in their work environment. These organizations are looking for potential opportunities for emerging capabilities and innovation (Alshayb, 2015).

Dimensions of Organizational Agility In the business market, agility is created in a variety of ways. For example, Goldman and his colleagues point to the continued and consistent adaptation to customer needs 
by offering a wide range of products and services (Goldman, 1995). Another approach emphasizes timely preventive actions designed to create and access market opportunities or to shake competitors' movements (Daveni, 1995). Finally, it can be argued that organizational agility requires an emphasis on organizational adaptability, ongoing awareness of opportunities and environmental threats, and the intrinsic capability to take advantage of opportunities and minimize the negative impact of potential threats. The following aspects of organizational agility can also be discussed:

1. Agile Position The agile position is seen as a shared mentality that instills a spirit of competition, dynamism and agility. This mentality in turn leads to the determination to invest and design the levers needed for quick and reconfiguration. This ultimately leads to specific action and, instead of waiting for the organization to change its external events, puts itself in a position of continuous change and all employees are responsible for organizational success (Hamel, Prahalad, 2014).

2. Market recognition: The second dimension of agility is the ability of the organization to identify and influence emerging opportunities and threats. This is the ability to be active, not reactive and passive. This suggests that opportunities and threats are not only in the changing expectations of customers, but also in potential competitors' activities and reactions and in potential product changes. In fact, one should not only be surprised at the progress and success of other organizations. Rather, it should seek to maximize the ability of the organization to influence or control important environmental factors (Goldman, 1995).

3. Rapid Response Equipment's: This dimension refers to the ability to adapt quickly. But here's the trouble-free speed. In fact, the speed of response is a kind of intelligence created by the second dimension, namely, market research and understanding. Equipping and arming for rapid response involves the rapid and timely reorientation of human, organizational, physical, and financial resources in the organization (Goldman, 1995). This section deals with some definitions and concepts of organizational excellence;

Definition of Organizational Excellence: Excellence in the word means elevating and excelling, and organizational excellence means an organizational commitment to the sustainable and sustainable growth of the company in order to gain customer satisfaction and to continually increase the profitability of the company in an inclusive and supportive national environment. Organizational excellence is subject to the special conditions, culture, internal and external environment and business, characteristic of the organization's human resources, strengths and weaknesses, opportunities and threats that the organization encompasses (Nakhaeinejad, 2009). The model of excellence is a management structure that promotes improvement and improvement by relying on the basic principles and concepts and paying attention to the main criteria of total quality management and the self-evaluation system. The Excellence Model is a tool for measuring systems deployment in the organization and for self-assessment and guidance that identifies and determines the path of activity for managers to improve performance. Therefore, the key message of the model of excellence relies on answering two questions, how this model is identified as an appropriate and rational management structure and who can play a key role in this chain of interactions. At the first level of this model the general goals and at the next level the general goals are decomposed into quantifiable quantities and scales. Performance appraisal is one of the main tasks of any organization and one of the aspects of performance management, which has been implemented in the past through the use of financial indicators (Del ghavi, 2007). Here are some of the definitions and concepts of urban management;

Concept of Urban Management in Different Dimensions: Urban management can be defined in two ways, one content and the other procedural. From a content perspective, urban management is seen as the implementation of policy, that is, as a public affairs office, and from a procedural point of view, urban management is defined by performance and certain other features that go beyond the concept, plus For the World Bank, urban management has a quasi-commercial approach to government that may lead to more efficient and efficient use of resources. Urban management is also a set of activities that interact and shape 
the economic, physical and social development of urban areas. Therefore, the main task of urban management is to intervene in these areas with the aim of promoting economic development and it is the well-being of the people as well as the provision of services. Rogers has a similar view; he believes that the purpose of urban management is to manage the components of the urban system, in a way that enables the system to operate daily and, by encouraging all sorts of economic activities, provide bedrock so that residents can meet their basic needs, including housing, Access to public goods or services as well as revenue-generating opportunities. Finally, urban management is a strategic responsibility that is coupled with operational outcomes and outcomes (Gill, 2017).

Elsewhere, urban management is considered synonymous with growth and development management. At times, even the expression "public resource management" of urban management is considered equivalent. Instead of "environmental management" or other "service management", urban management is synonymous with providing public services, which is the primary task of the local government, thus providing a unified content definition of urban management with different features that but it is difficult to say, but the common definitions provided for this concept are somewhat of a unified nature. If the city is to be considered as an organization, then it is necessary to have at its head an element of future planning and the current affairs department and this element can be called city management. There are many issues in cities that need to be resolved. The existence of urban management is considered essential, such as how the future of the city will expand, the provision of public services (water, electricity and sanitation), the construction of public centers with recreational-cultural and sporting functions, and ultimately the construction of streets and alleys. It also needs to make plans, organize urban activities, oversee activities, and even create the necessary incentives for the city's management and other organizations and citizens to optimally do things. Also, another definition states that urban management is a process of continuous responsibilities, actions, and communications to achieve specific operational goals at the level of urban communities. Creating this process and achieving its operational goals requires a defined, transparent, and accountable organizational framework for all urban community actors, who have a more comprehensive view of urban management, believing that urban management, should be a process, Comprehensive and holistic, inclusive and integrated. Inclusiveness means that it encompasses all urban actors and actors, holistic and holistic in a way that encompasses all aspects of policy-making, planning, organizing and monitoring, and avoids partiality and integration. That is to say, urban development as the goal of urban management is to be seen as the development of an institution that refers to the capacity and capability of the urban management organization in urban development and is related to the degree of decentralization in the urban management process. In this case, the urban management organization will also be sustainable and will create a sustainable urban environment (Gill, 2017).

Urban Management Excellence: Most people are members of an organization, such as a college, sports team, a music group, a theater group, a religious organization, or an enterprise. Some of these organizations are highly formalized. Some have informal status. But they are all made up of components that see their benefits in working together to achieve a common goal. Cities, as an organization, are made up of different components that work together to achieve a common goal that is sustainability in all aspects. These cities also have undeniable interactions with their surroundings and interactions. That is why these cities are sometimes affected by dominant communication and inevitably change. Urban management efforts to improve the well-being of citizens have always been affected by the problem of urban economy. One way to achieve sustainable development in the urban economy is to achieve selfsufficiency in the city's revenue affairs. This is not only possible through temporary solutions such as attracting government support and loans, but also requires long-term and comprehensive planning to achieve it. One of the prerequisites for creating a long-term plan for a city is having sufficient information about the city's resources and potentials, which can only be achieved through comprehensive city analysis. One of the techniques that can be effective in conducting this analysis, which is believed to be in the 
direction of excellence, is the strategic management technique of Tehran management (Papeli Yazdi, 2007).

One of the many problems that most Third World cities face today is the shutdown of their systems. Explaining that city officials neglect interactions between systems and their interactions and refuse to analyze the status of their city. This issue is one of the important reasons for poor urban management and its result in critical issues such as marginalization, lack of economic self-sufficiency, lack of recognition of strengths and advantages, lack of improvement of deficiencies in the urban system, inappropriate use of opportunities and Threat management is emerging. Systems theory if contemporary science is examined from a general perspective, it is difficult to find a word that is as much used as the system. Systems theory is a methodology of dealing with reality and deals with the application of concepts related to systems and systems ideas. This methodology is referred to as systematic approach or systematic approach or systematic approach. Systemic approach, that is, system theory, is a rapidly evolving process in modern science and technology and a general scientific and methodological concept. In this approach, subject matter is examined and researched into homogeneous and interrelated components that aim not only to identify them but also to manage and shape them, and organized to be our favorite. In the field of systems theory, philosophical and methodological issues, this theory has received a great deal of worldwide scientific activity (Papeli Yazdi, 2007).

Mehdi Pour, Savari, and Jalilvand (2017) concluded in a study entitled "Investigating and Evaluating the Dimensions of Organizational Agility, a Case Study of Khuzestan Province Youth and Sports Administration" that concluded that Khuzestan Youth and Sports Directorate General in terms of flexibility and competence of It has good agility but in terms of speed and responsiveness it does not have optimal agility. Sanat Gray, Peikani Mehraban \& Gholamzadeh (2016) in a study entitled "Investigating and Testing the Organizational Agility Model in the Petroleum Pension Fund", they concluded that leadership agility (with five components of agility setting, cooperative creativity, agility in creativity, agility). In agility and synergy); agility in serving four components (speed, competence and quality, responsiveness, flexibility and innovation); staff agility (with four components of intelligence and awareness, flexibility and partnership, competence); agility culture (With five components of collaboration, nurturing, diversity, competence, innovation, creativity and transparency) Agility in organizational processes (with three components of structure Flexible and up-to-date rules and procedures, new procedures and processes; Agility in ICT (with up-to-date hardware and software components; up-to-date software and programs). Sepasi (2012) in a study entitled "Aggregation of Banks and Providing a Tool for Measuring Organizational Agility in Iranian State Banks" (Measuring the Readiness of Iran Export Bank) concluded that Export Bank of Iran was prepared for Agility The organization has and can move towards the agility of its organization.

Nafei, Wageeh (2016) has conducted a research entitled "The Role of Organizational Agility in the Promotion of Organizational Excellence: A Study in the Egyptian Communication Sector". This study was done on 250 employees of communication department. The results showed that there is a significant relationship between all three dimensions of organizational agility with organizational excellence. Algama (2011), entitled "Creating an Environment for Organizational Learning and Agility", concluded that leaders create the environment for organizational learning and workforce and participate in organizational learning, successful planning, and development of future organizational leaders. Also, senior environmental leaders create organizational agility to improve organizational performance, mission and strategic goals, innovation, performance leadership and organizational agility, including leadership, knowledge and environmental awareness, strategic planning process, processes the work systems know.

Research questions: From the Perspective of Personnel, Managers and Experts of Municipality of District 4 of Tehran What Are the Influential Components of Urban Management Transformations in Tehran's White Soil Area? From the Perspective of Personnel, Managers and Experts of Municipality of 
District 4 of Tehran What Are the Influencing Components of the Effectiveness of Agility of Urban Management in Tehran's White Soil Area? What is the appropriate model for the effectiveness of organizational excellence and agility in urban management on the physical, social and cultural dimensions of Tehran white soil area? To what degree is the appropriateness of the proposed pattern?

\section{Methodology}

Since the components related to the effectiveness of organizational excellence and agility in urban management need to be revealed from the perspective of managers and urban authorities in order to measure them and then design a model, use a qualitative-quantitative research approach. Was. For this purpose, the exploratory method of mixed research method is used. The mixed research method consists of both qualitative and quantitative steps. In the present study, the researcher used the qualitative research method in the first stage, and then applied the quantitative approach to the qualitative stage. One of the three methods of mixed research was selected: intertwined exploratory anatomy, and the third method. Then quantitative research approach was used to assess the suitability of the proposed research model by descriptive-analytical method. So here, based on the executive priority of the research process, first the qualitative research method steps and then the quantitative research method steps are used. The qualitative research method was explored in order to find out about the 'indefinite position'. This was done through semi-structured interviews The "focus groups" of qualitative data on factors affecting organizational excellence and effectiveness in urban management were collected so that after interviewing 10 experts and experts in the field of urban management, extracting elements affecting organizational agility and excellence in urban management and then extracting Qualitative analysis of data collected on verb status Dimensions and Elements of Effectiveness of Organizational Excellence and Agility in Urban Management were categorized and a questionnaire was developed in line with the elements presented on the effectiveness of Organizational Excellence and Agility in Urban Management. The quantitative analysis of the data obtained from the questionnaire can be used to develop an appropriate model, Since in the qualitative phase of research, the proposed components for measuring the effectiveness of organizational excellence and agility in urban management on physical, social and cultural dimensions of Tehran white soil area were represented, In quantitative phase, using descriptive-analytical method through factor analysis techniques. Structural equations were used to describe the model in the research community as well as to study the relationships between the concepts and components of the proposed model. The statistical population included all 632 municipal employees of Tehran city with 632 employees as contractors and managers, who They were serving in 1977. Considering the population size in quantitative stage 632 and referring to Morgan sample size estimation table, the sample size was 240 persons. 264 questionnaires were distributed by stratified random sampling method. The researcher-made questionnaire consisted of 32 items of Urban Management Excellence Questionnaire, 41 items of Agility in Urban Management Questionnaire and 27 items of Physical and Social and Cultural Status Assessment Questionnaire, validity of which was confirmed and then Cronbach's alpha reliability value was 0.802 from the experimental run of 40 statistical samples. For Urban Management Excellence Questionnaire, reliability was 0.816 for Urban Management Agility Questionnaire and 0.849 Reliability for Physical, Social and Cultural Status Questionnaire. Descriptive and inferential statistical methods were used to answer the research questions. Descriptive statistics were used to extract the frequency and percentage of response to each option and to compare and understand the values of the findings. At the inferential statistics level, factor analysis statistical method was used to identify present variables, path analysis method using AMOS software. 


\section{Findings}

Question 1: From the Perspective of Personnel, Managers and Experts of Municipality of District 4 of Tehran What Are the Influencing Components of Urban Management Transformations in Tehran's White Soil Area?

Exploratory factor analysis is used to answer this question, in which many of the dependent variables are reduced to a smaller number of hidden or present dimensions and its main purpose is to observe the principle of economics and save through the application of the smallest. Explanatory concepts are used to explain the maximum amount of variance shared in the correlation matrix. The data matrix for factor analysis should contain meaningful information. The significance of the information in a matrix is determined by the chi-square Bartlett test, and the significance of the chi-square test and the Bartlett test is the minimum requirement for factor analysis. Therefore, prior to using exploratory factor analysis, Bartlett test was used to confirm the functionality of the items.

Table1. Bartlett test

\begin{tabular}{cc}
\hline KMO test & $913 / 0$ \\
\hline Approximate amount of Chi Oscar & $045 / 22625$ \\
\hline Df & 239 \\
\hline Sig & $000 / 0$ \\
\hline
\end{tabular}

According to Table 1 and the value of KMO index which is 0.913 and is greater than 0.6 , it can be concluded that the number of samples is sufficient for factor analysis. Is $\mathrm{P}=0$ ) and, given its smaller size ( $\mathrm{p}$ $<0.05)$, the null hypothesis is rejected. In the Bartlett test, the null hypothesis is that the variables are only correlated with themselves, and the rejection of the null hypothesis implies that the correlation matrix has meaningful information and there are at least the necessary conditions for factor analysis, so exploratory factor analysis can be performed on the questions. Questionnaire was administered.

Table2. Exploratory Factor Analysis Related to Urban Management Excellence Questionnaire Items

\begin{tabular}{|c|c|c|c|c|c|}
\hline questions & Factor 1 & Factor 2 & Factor 3 & Factor 4 & $\begin{array}{c}\text { Extractive } \\
\text { subscription }\end{array}$ \\
\hline 1 & & & & $0 / 612$ & $0 / 808$ \\
\hline 2 & & & & $0 / 575$ & $0 / 844$ \\
\hline 3 & & & & $0 / 589$ & $0 / 841$ \\
\hline 4 & & & $0 / 548$ & & $0 / 858$ \\
\hline 5 & & & $0 / 507$ & & $0 / 763$ \\
\hline 6 & $0 / 597$ & & & & $0 / 599$ \\
\hline 7 & $0 / 746$ & & & & $0 / 658$ \\
\hline 8 & $0 / 761$ & & & & $0 / 676$ \\
\hline 9 & $0 / 782$ & & & & $0 / 738$ \\
\hline 10 & $0 / 692$ & & & & $0 / 710$ \\
\hline 11 & & & $0 / 702$ & & $0 / 667$ \\
\hline 12 & & & $0 / 762$ & & $0 / 764$ \\
\hline 13 & & $0 / 721$ & & & $0 / 716$ \\
\hline 14 & & $0 / 762$ & & & $0 / 697$ \\
\hline 15 & & & & $0 / 760$ & $0 / 758$ \\
\hline 16 & & & & $0 / 798$ & $0 / 715$ \\
\hline 17 & & & & $0 / 802$ & $0 / 743$ \\
\hline 18 & & & & $0 / 743$ & $0 / 654$ \\
\hline 19 & & & & $0 / 551$ & $0 / 661$ \\
\hline 20 & $0 / 778$ & & & & $0 / 657$ \\
\hline 21 & & $0 / 555$ & & & $0 / 648$ \\
\hline 22 & & $0 / 711$ & & & $0 / 653$ \\
\hline 23 & & $0 / 682$ & & & $0 / 667$ \\
\hline
\end{tabular}


Volume 2, Number 3, Iranian journal of educational Sociology $\mid 192$

\begin{tabular}{|c|c|c|c|c|c|}
\hline 24 & & & & $0 / 624$ & $0 / 676$ \\
\hline 25 & & & $0 / 556$ & & $0 / 582$ \\
\hline 26 & & & $0 / 695$ & & $0 / 606$ \\
\hline 27 & $0 / 720$ & & & & $0 / 698$ \\
\hline 28 & $0 / 742$ & & & & $0 / 686$ \\
\hline 29 & & & $0 / 774$ & & $0 / 708$ \\
\hline 30 & & $0 / 688$ & & & $0 / 597$ \\
\hline 31 & & $0 / 770$ & & & $0 / 639$ \\
\hline 32 & & $0 / 551$ & & & $0 / 521$ \\
\hline 33 & - & - & - & - & $0 / 450$ \\
\hline $\begin{array}{c}\text { Special Agent } \\
\text { Value }\end{array}$ & $19 / 777$ & $6 / 387$ & $6 / 128$ & $22 / 776$ & - \\
\hline $\begin{array}{c}\text { The variance } \\
\text { explained by the } \\
\text { agents }\end{array}$ & $21 / 115$ & $7 / 603$ & $7 / 295$ & $27 / 923$ & - \\
\hline
\end{tabular}

The factor analysis test, after multiple rotations, provided 9 main factors with different factor loadings. An in-depth examination of the extracted coefficients revealed that out of 9 explored factors, only 4 factors had factor coefficients above 0.50. For this purpose, to fit the model of organizational excellence effectiveness in urban management on physical, social and cultural dimensions of the region Tehran white soil Factors whose extracted coefficients were less than 0.50 or had negative coefficients above 0.50 were excluded from the used factors and finally the four main factors that remained in the condition were the information. They are as described in Table 3. Extractive Subscription Amounts can also be seen from the data in the above table b Voting 1 for Question 33 is less than 0.50 , so the questions are excluded from the questionnaire. In other words, it can be concluded that the questions in the questionnaire are generally divided into 4 factors. Theoretical basics and background of the research conducted and expert opinions on the training of the four extracted factors were named as follows:

Table3. Introducing Factors Extracted from Urban Management Excellence Questionnaire

\begin{tabular}{llcl}
\hline Row & Factor & Number of questions & Selected name \\
\hline 1 & First & $6-7-8-9-10-20-27-28$ & Value added in the workplace \\
\hline 3 & Second & $13-14-21-22-23-30-31-32$ & $\begin{array}{l}\text { Proper leadership in the } \\
\text { workplace }\end{array}$ \\
\hline 4 & Third & $4-5-11-12-25-26-29$ & $\begin{array}{l}\text { Workflow process } \\
\text { management }\end{array}$ \\
\hline
\end{tabular}

Question 2: From the Perspective of Personnel, Managers and Experts of Municipality of District 4 of Tehran What Are the Factors Influencing the Effectiveness of Urban Management Agility in Tehran's White Soil Area?

Exploratory factor analysis is used to answer this question, in which many of the dependent variables are reduced to a smaller number of hidden or present dimensions and its main purpose is to observe the principle of economics and to save by applying the smallest. The explanatory concepts are intended to explain the maximum amount of variance shared in the correlation matrix. The data matrix for factor analysis should contain meaningful information. The significance of the information in a matrix is determined by the chi-square Bartlett test, and the significance of the chi-square test and the Bartlett test is the minimum requirement for factor analysis. Therefore, prior to using exploratory factor analysis, Bartlett test was used to confirm the functionality of the items. 
Table4. Bartlett test

\begin{tabular}{c|c}
\hline KMO test & $0 / 830$ \\
\hline Approximate amount of Chi Oscar & $5551 / 841$ \\
\hline Df & 239 \\
\hline Sig & $0 / 000$ \\
\hline
\end{tabular}

According to Table 4 and the value of KMO index which is 0.830 and greater than 0.6 it can be concluded that the number of samples is sufficient for factor analysis. On the other hand, the significance level of Bartlett test is equal to (0.000). Is $\mathrm{P}=0$ ) and, given its smaller size $(\mathrm{p}<0.05)$, the null hypothesis is rejected. In the Bartlett test, the null hypothesis is that the variables are only correlated with themselves, and the rejection of the null hypothesis implies that the correlation matrix has meaningful information and there are at least the necessary conditions for factor analysis, so exploratory factor analysis can be performed on the questions. Questionnaire was administered.

Table5. Exploratory Factor Analysis Related to Agility Questionnaire Items in Urban Management

\begin{tabular}{|c|c|c|c|c|c|c|}
\hline questions & Factor 1 & Factor 2 & Factor 3 & Factor 4 & Factor 5 & $\begin{array}{l}\text { Extractive } \\
\text { subscription }\end{array}$ \\
\hline 1 & $0 / 723$ & & & & & $0 / 775$ \\
\hline 2 & & & $0 / 804$ & & & $0 / 778$ \\
\hline 3 & & & $0 / 732$ & & & $0 / 663$ \\
\hline 4 & & $0 / 507$ & & & & $0 / 589$ \\
\hline 5 & & $0 / 649$ & & & & $0 / 697$ \\
\hline 6 & & & $0 / 732$ & & & $0 / 683$ \\
\hline 7 & & $0 / 811$ & & & & $0 / 748$ \\
\hline 8 & & $0 / 556$ & & & & $0 / 561$ \\
\hline 9 & $0 / 702$ & & & & & $0 / 664$ \\
\hline 10 & & & & $0 / 725$ & & $0 / 746$ \\
\hline 11 & & & & $0 / 685$ & & $0 / 631$ \\
\hline 12 & & & $0 / 778$ & & & $0 / 688$ \\
\hline 13 & & & $0 / 803$ & & & $0 / 725$ \\
\hline 14 & & $0 / 768$ & & & & $0 / 708$ \\
\hline 15 & & $0 / 801$ & & & & $0 / 709$ \\
\hline 16 & & $0 / 632$ & & & & $0 / 646$ \\
\hline 17 & & $0 / 649$ & & & & $0 / 522$ \\
\hline 18 & & $0 / 551$ & & & & $0 / 628$ \\
\hline 19 & $0 / 509$ & & & & & $0 / 663$ \\
\hline 20 & & & $0 / 572$ & & & $0 / / 590$ \\
\hline 21 & & & $0 / 557$ & & & $0 / 518$ \\
\hline 22 & & & $0 / 518$ & & & $0 / 596$ \\
\hline 23 & & $0 / 516$ & & & & $0 / 584$ \\
\hline 24 & & $0 / 591$ & & & & $0 / 640$ \\
\hline 25 & & $0 / 575$ & & & & $0 / 513$ \\
\hline 26 & & $0 / 511$ & & & & $0 / 550$ \\
\hline 27 & & $0 / 620$ & & & & $0 / 717$ \\
\hline 28 & & $0 / 639$ & & & & $0 / 601$ \\
\hline 29 & & & & & $0 / 576$ & $0 / 509$ \\
\hline 30 & & & & & $0 / 626$ & $0 / 638$ \\
\hline 31 & & & & & $0 / 655$ & $0 / 659$ \\
\hline 32 & & & & $0 / 587$ & & $0 / 665$ \\
\hline 33 & & $0 / 584$ & & & & $0 / 556$ \\
\hline 34 & & $0 / 653$ & & & & $0 / 720$ \\
\hline 35 & & $0 / 668$ & & & & $0 / 706$ \\
\hline 36 & & $0 / 601$ & & & & $0 / 785$ \\
\hline
\end{tabular}




\begin{tabular}{|c|c|c|c|c|c|c|}
\hline 37 & & $0 / 573$ & & & & $0 / 708$ \\
\hline 38 & & $0 / 630$ & & & & $0 / 778$ \\
\hline 39 & - & - & - & - & - & $0 / 486$ \\
\hline 40 & - & - & - & - & - & $0 / 424$ \\
\hline 41 & - & - & - & - & - & $0 / 399$ \\
\hline $\begin{array}{l}\text { Special Agent } \\
\text { Value }\end{array}$ & $2 / 948$ & $26 / 195$ & $7 / 056$ & $2 / 559$ & $1 / 981$ & - \\
\hline $\begin{array}{l}\text { The variance } \\
\text { explained by } \\
\text { the agents }\end{array}$ & $3 / 472$ & $28 / 139$ & $8 / 026$ & $3 / 840$ & $2 / 192$ & - \\
\hline
\end{tabular}

The factor analysis test, after multiple rotations, provided 11 main factors with different factor loadings. An in-depth study of the extracted coefficients revealed that out of 11 explored factors, only 5 factors had factor coefficients above 0.50 . Tehran white soil Factors whose extracted coefficients were less than 0.50 or had negative coefficients above 0.50 were excluded from the factors used and finally the 5 main factors that remained in the condition were the information. They are as described in Table 6. Extractive share value can also be seen from the data in the table above A vote of 3 questions with a score of 40-40-41 is less than 0.50 , so the questions are excluded from the questionnaire. In other words, it can be concluded that the questionnaire questions are generally divided into 5 factors. Considering the content of the questions and the theoretical background and background of the research, the expert opinions on the training of the five extracted factors were named as follows:

Table6. Introducing Factors Extracted from Urban Management Agility Questionnaire

\begin{tabular}{llcl}
\hline Row & Factor & Number of questions & Selected name \\
\hline 1 & First & $1-9-19$ & Accountability to clients \\
\hline 2 & Second & $24-25-26--7-8-14-15-16-17-18-23-4-5$ & Continuous staff growth and \\
& & $27-28-33-34-35-36-37-38$ & learning \\
\hline 3 & Third & $2-6-3-12-13-20-21-22$ & Competence in the post \\
\hline 4 & Fourth & $10-11-32$ & Workplace flexibility \\
\hline 5 & Fifth & $29-30-31$ & Speed of doing things \\
\hline
\end{tabular}

Question 3: What is the appropriate model for the effectiveness of organizational excellence and agility in urban management on the physical, social and cultural dimensions of Tehran white soil area?

In order to draw an appropriate model of effectiveness of organizational excellence and agility in urban management, on the physical, social and cultural dimensions of Tehran white soil area, according to the identified factors, path analysis method has been used by AMOS software. Which path is more important or more significant. Path correlations are calculated based on the standardized regression coefficient. As one variable is assumed to be a function of the other variables and its regression model is plotted. To obtain estimates of the main path coefficients, it is sufficient to return any dependent (endogenous) variable to the directly affected variable. In other words, for estimations of each of the specified paths, standardized regression coefficients (or path coefficients) are calculated. However, before applying this method, the main assumptions must be made of the use of this method, the most important of which are:

1)Enough sample numbers. 2) Distance and relativity scales for model variables. 3)Normality of data 4) The uniqueness of variables.

Based on the data of the above tables and the value of KMO index which is 0.913 and 0.830 for urban excellence and agility in urban management questionnaires, respectively, it is possible to conclude the sample number. Sufficient for factor analysis, this adequacy of sample numbers can be generalized to path analysis for factor analysis. Distance and Relative Scale for Model Anchors: Given the fact that the four factors explored in the Urban Management Excellence Questionnaire and the 5 factors explored in the Urban Management Agility Questionnaire combine all the questions into each factor, this assumption is also followed. That is, questionnaire questions that have a rating scale have been transformed into a 
distance scale after being computed. The Kolmogorov-Smirnov test was used to determine the normality of the variables, the results of which indicated that all the variables under test had a normality assumption and followed the normal distribution. This assumption implies that a variable is made up of a combination of at least two sub-variables and that the sub-variables have a similar sign-like relationship to the other variables, and that, as seen in the tables above, each variable consists of more than two questions. Is.

Considering each of the assumptions examined in all the factors and qualifying the use of Path Analysis to develop a suitable model for the effectiveness of organizational excellence and agility in urban management, on physical, social and cultural dimensions of Tehran White Soil The obtained variables were entered into AMOS software to graphically represent the direct and indirect coefficients of the variables. The graphical result of implementing AMOS software to draw an appropriate model for the effectiveness of organizational excellence and agility in urban management, on the physical, social and cultural dimensions of the Tehran white soil area is as follows.

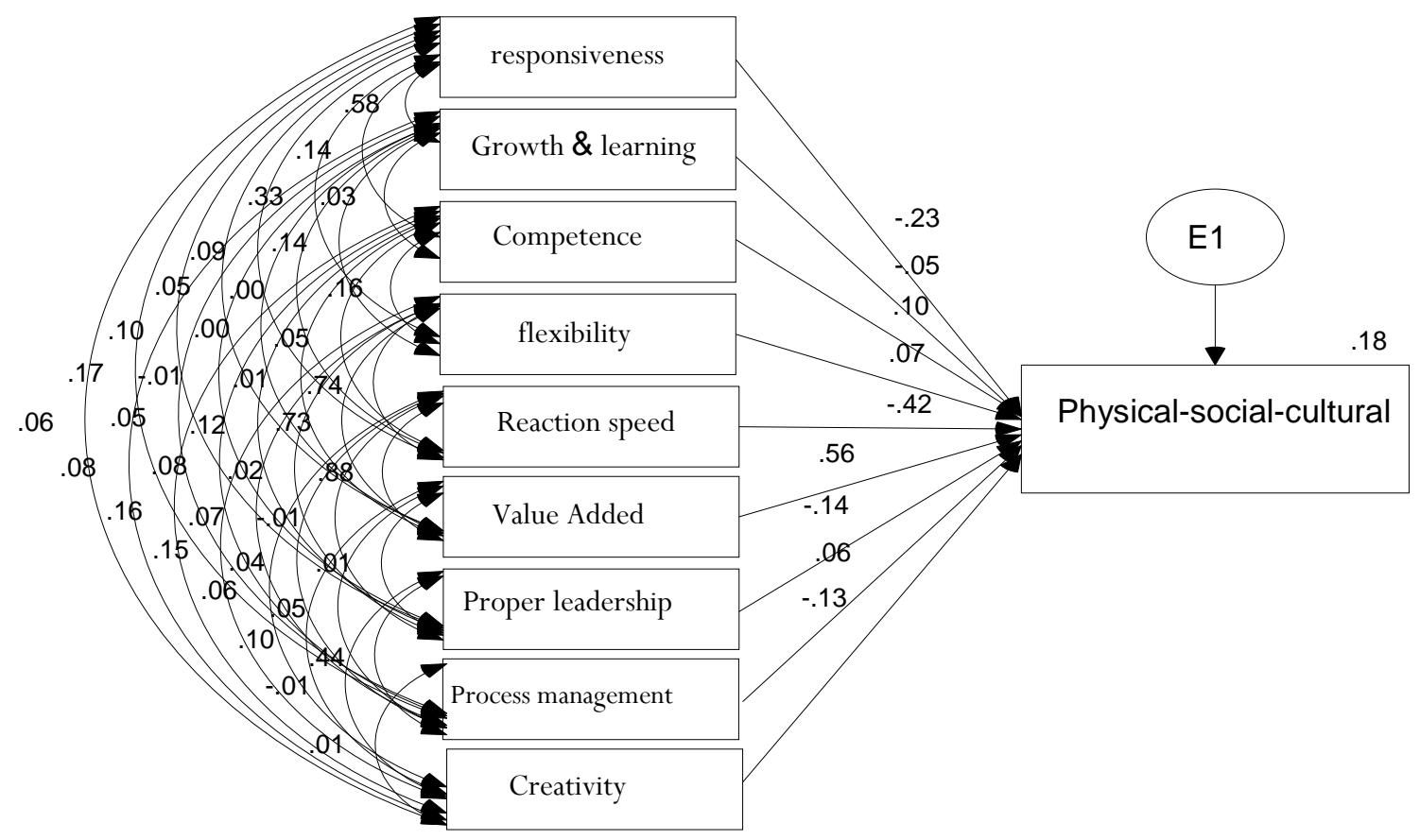

Chart1. Appropriate Model of Organizational Excellence and Agility in Urban Management, on Physical, Social and Cultural Dimensions of Tehran White Soil Area

Question 4: How appropriate is the proposed pattern? GFI (Goodness of fit index) is used to check the suitability of the proposed model. It measures the relative amount of variances and covariance's jointly through the model. The range of GFI variations is between zero and one, and the pattern will fit the pattern whose GFI value should be equal to or greater than 0.90. Given the GFI coefficient of 0.937 and greater than 0.90 , it can be concluded that the proposed model of organizational excellence and agility in urban management has a high degree of proportionality on physical, social and cultural aspects of Tehran white soil area. 


\section{Discussion}

Answering the first question: Considering the content of the questions and the theoretical background and background of the research done and adopting the opinions of expert experts on the factors influencing the development of urban management 4 factors (value added in the workplace, proper leadership in the workplace, Process management in the workplace and fostering creativity in the workplace have been extracted and named. In explaining this finding, it can be said that the model of organizational excellence is an evaluation framework that uses urban mobility and management activities in municipalities toward continuous improvement. It goes well and the organization using the standards of organizational excellence model can accomplish its activities Identify areas for improvement and implement improvement projects to achieve service excellence. This finding is in line with the findings of Atafar, Forouzan (2012) and Shahin (2014). Factor analysis test after multiple rotations finally according to the content of questions and theoretical background and research background and expert opinions on 5 factors training (customer responsiveness, staff growth and continuous learning, competency in appointments, flexibility Adaptability in the workplace and the speed of doing things) were extracted and named. In explaining this finding it can be said that according to the Where agility means the ability to respond quickly and successfully to environmental change, the municipality must also look for agility as a manufacturing organization to compete in the 21 st century because agility enhances the organization's ability to deliver high-quality services, providing flexibility. Increasing speeds up work and leads employees to learn more to adapt to changing circumstances and leads managers to select the right staff. Also, given that today's world is changing and all organizations must align with today's world in order to grow and satisfy customer needs and employee satisfaction, municipalities must be able to maintain the desired speed and flexibility. Survival when faced with internal and external events of their organization. Finally, it can be deduced that when municipalities pay attention to the factors of organizational agility and the organization has agile staff, the speed of responding to clients will increase, and municipal staff and managers will seek to learn new science and grow their information as they grow. Technology will be updated, staff flexibility will be improved, and eventually the speed will be increased. Urban management will also have these factors in municipalities, and the city will also benefit from agile urban management. The agility mentioned above will benefit you This finding is in line with the findings of Soltani research (2013) in terms of competence, accountability and flexibility. In addition, in terms of flexibility, speed in doing things, growth and learning is in line with the findings of Abbas Pour, et al. (2013). Also, in terms of flexibility, responsiveness to clients, speed and competence are consistent with the results of Shahin (2014). In addition, in terms of accountability, flexibility, competences are in line with the results of Mehdi Pour et al (1396). Also in terms of agility in terms of activities and speed are in line with the results of Nafei research (2016). Suitable for organizational excellence and organizational agility in urban management, the physical, social and cultural aspects of the Tehran white soil area were drawn. This model includes the components of accountability, growth and learning, competence, flexibility, speed of action, value-added, sound leadership, process management and nurturing creativity. In explaining this finding it can be said that in order to enhance the effectiveness of urban management, different pillars should be used. Urban management should be equipped with the components of organizational agility and organizational excellence and managers should strive to develop the dimensions of accountability, growth and learning, competence, flexibility, speed of action, value-added, sound leadership, process management and creativity. To be promoted to the highest level in this field in the field of finance and planning education In line with the leadership component, this finding is consistent with the findings of Shahin (2014). This finding is consistent with the findings of competence, accountability, and flexibility with Soltani (2013) findings. In addition, flexibility, speed In doing business, growth and learning is in line with Abbas Pour, et al (2013) research findings. In addition, leadership and process align with Algama (2011) research findings, Also, in terms of flexibility, responsiveness, speed, and competence. This is consistent with the results of 
Shahin research (2014). In addition, in terms of responsiveness, flexibility, competence is in line with the results of Mehdi Pour et al (1396). Also in terms of agility in performance and speed is in line with the results of Nafei research (2016). Based on the obtained data and GFI coefficient equal to 0.937 and greater than 0.90 , it can be concluded that the proposed model of organizational excellence and agility in urban management, based on physical, social and cultural dimensions of Tehran white soil area of degree, High fitness. No finding was found to confirm or reject this finding.

According to the findings of the present study, the following suggestions are made to the staff and managers and experts of the Municipality of Tehran's District 4:

1. Since the researcher in the present study concluded that in formulating the model of organizational excellence effectiveness in urban management affecting physical, social and cultural dimensions, value added in the workplace is effective, so it is suggested to municipal managers to allocate and deploy financial resources to meet the strategic goals of the organization. Also, senior executives take action on the values of the organization and inform employees of the organizational goals associated with their activities by conducting numerous meetings and meetings.

2-Because the researcher in the present study concluded that in formulating the model of organizational excellence effectiveness in urban management on physical, social and cultural dimensions, effective leadership in the workplace is effective, so it is suggested to the municipal management team that Attend specialized meetings related to urban management, inform municipal deputies and staff on the results of the latest surveys, as well as provide ongoing reporting and face-to-face meetings for the municipal management team, and more Engage in different processes and processes of the organization.

3. Because the researcher in the present study concluded that in formulating the model of organizational excellence effectiveness in urban management on physical, social and cultural dimensions, process management is effective in the workplace, so it is suggested to municipal managers to continually improve processes. An organization based on identifying opportunities and needs existing and appropriate by analyzing operational data and existing reports.

4-Because the researcher in the present study concluded that in formulating the model of organizational excellence effectiveness in urban management on physical, social and cultural dimensions, creativity in the workplace is effective, so it is suggested to municipal managers that different conditions and opportunities. Create an organization where employees have the opportunity to be creative and value their creativity through various rewards. 


\section{References}

Abbas Pour A, Aghazadeh A, Bagheri Karachi A. (2013) Designing a Desirable Model for Achieving Organizational Agility in the Universities.

Algama K. (2011). Creating a culture for organization learning and agility.

Alshayb M. (2015) An empirical study of system design instability metric and desin evolution in an agile software process. Journal of systems and software. and Computer-Integrated Manufacturing, 47: 495-503.

Atafar A, Forouzan B. (2012). Evaluation of Organizational Excellence of Isfahan Qa'el Sepahan Engineering Company Based on Peters \& Waterman Model of Production and Operations Management, 4(1): 102-85.

Bagherzadeh M R. (2010). Investigating Agility Capabilities in Government Organizations (Case Study of Mazandaran Post Office), Managerial.

Bandarian R. (2013). Agility, Why and How, First International Management Conference.

Burkpour N, Asadi I. (2009). Urban Governance and Governance, Tehran: Research University of Art.

Daveni R. (1995). Coping with Hyper competition: Utilizing the New 7s Framework. Academy of Management Exective, 9(3): 45- 60.

Del ghavi A. (2007). Principles and Foundations of EFQM Organizational Excellence Model, Dissertation, Organizational Excellence Model in Rail locomotive repair factories, Tehran.

Ebrahimian Jollodar S Y, Ebrahimian Jollodar S M. (2011). Organizational Agility: Response Speed and Organizational Flexibility, Human Development of Police, (39): 34-13.

EFQM (1999). The EFQM Excellence Model, EFQM,Bruxelles

Gholamzadeh D. (2016) Investigating and Testing the Agility Model in the Petroleum Pension Fund.

Gholipour A. (2011) Sociology of Organizations, Tehran: Publishing and Publishing University Books, Pos.

Gill A. (2017). Agile Manu faction: concept and framework, Agile manufacturing: the 21 st century competitive strategy.

Goldman S. (1995) Agile completions and virtual organizations, Kenneth van no strand Reinhold international Thomas publishing and London.

Gunaskaran A. (1999). "Agile manufacturing: A framework for research and development". International Journal of Production Economics, 62(1): 87-105.

Hamel G, Prahalad CK. (2014). Competing for the Future. Harvard Bussiness Review, July- August, 12-18.

Jafarnejad A, Shekhi B. (2007). Organizational Agility and Agile Production ", Mehraban Book Institute. Publication, First Edition, p. 33.

Jafarnejad A. (2015) Investigating the Role of Inter-organizational Factors in Explaining a Model for Converting Current Organizations into Agile Organizations in the Electronic and Telecommunication Industries of Iran. Journal of Management Culture.

Kidd P T (1994). A 21st century paradigm in agile manufacturing: Forging new frontiers, Addison- Workingham

Mehdi Pour A, Savari F, Jalilvand J. (2017) "Evaluation and Evaluation of Organizational Agility Dimensions, Case Study of Khuzestan Youth and Sports Administration" Journal of Physiology and Management Research in Sport, 9(1):125-136.

Mohammadi A, Amiri Y. (2012) Presenting an Interpretive Structural Model of Agility through Information Technology in Manufacturing Organizations, Information Technology Management, 4.

Nafei L Wageeh A. (2016) The Role of Organizational Agility in Enhancing Organizational Excellence: A Study on Telecommunications Sector in Egypt International Journal of Business and Management; 11(4).

Nakhaeinejad M. (2009). A Review of the Concepts and How Organizational Excellence in the Police Force, Quarterly Journal of Human Development, (12).

Nazemzadeh S A. (2015) Tomorrow's Organizations, Agile Organizations, Reviewed in June 94.

Papeli Yazdi M H. (2007). "Theories of the City and the Periphery", Tehran: Post Publication.

Sanat Gray H, Peikani Mehraban H, Gholamzadeh D. (2016) "Investigating and Testing the Agility Model in the Petroleum Pension Fund" Journal of Human Resource Management in Oil Industry, 8(29).

Sepasi N. (2012) "Title of Bank Agility and Providing a Tool for Measuring Organizational Agility in Iranian State Banks" (Iranian Export Bank Readiness Scale), Journal of Executive Management Research, 5(10).

Shahin A. (2014). The Relationship between Organizational Excellence Enablers and Organizational Agility Capabilities in Isfahan Public Universities. A New Approach in Educational Management.

Sharifi H, Zhang Z. (1999), A methodology for achieving agility in manufacturing organization, international journal of production economics, (62): 7-22.

Soltani Gh. (2013) Determining the Status of Organizational Agility Capabilities in Agricultural Conversion and Supplementary Industries by Fuzzy Approach. Journal of Agricultural Economics and Development, (4).

Yusuf Y Y, Sarhadi M, Gunasekaran A. (1999). Agile manufacturing: The drivers, concepts and attributes, International Journal of Production Economics; 62(1- 2): 33- 43 